\title{
Noninvasive Positive Pressure Ventilation in Patients with Acute Respiratory Failure
}

\author{
Lt Col S P Rai*, Brig B N Panda+, Lt Col K K Upadhyay\#
}

\begin{abstract}
Noninvasive positive pressure ventilation (NIPPV) delivered by nasal route or facemask is increasingly being used in the management of patients with acute respiratory failure. 45 patients ( 29 males, 16 females) with a mean age of 68.32 years (range 29 to 82 years) having acute onset hypoxemic and/or hypercapnic respiratory failure who were managed with NIPPV in a tertiary care centre of Armed Forces were analyzed retrospectively. Patients with hemodynamic instability, coma and uncooperative patients were excluded from study. Etiology of acute respiratory failure was acute exacerbation of chronic obstructive pulmonary disease (COPD) in 29 patients, adult respiratory distress syndrome (ARDS) in 4 patients, severe kyphoscoliosis in 2 patients, interstitial lung disease (ILD) in 4 patients, lung contusion with pneumonia in 1 patient, thoracoplasty in 1 patient and difficult weaning in 4 patients. Initial resting arterial blood gases showed mean arterial oxygen tension $\left(\mathrm{PaO}_{2}\right) 61 \mathrm{mmHg}(\mathrm{range} 45$ to 78 $\mathrm{mmHg}$ ), mean arterial carbon dioxide tension $\left(\mathrm{PaCO}_{2}\right) 75.2 \mathrm{mmHg}$ (range 32 to $127 \mathrm{mmHg}$ ) and mean arterial pH-7.26 (range 7.03 to 7.45). Mean inspiratory positive airway pressure (IPAP) was $14 \mathrm{~cm} \mathrm{H}_{2} \mathrm{O}$ (range 10 to $20 \mathrm{~cm} \mathrm{H}_{2} \mathrm{O}$ ). Mean expiratory positive

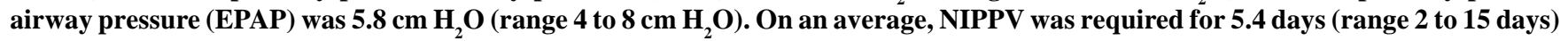
prior to discharge. 11 patients required long term intermittent NIPPV along with domiciliary oxygen therapy. 9 patients died out of which 4 patients had advanced interstitial lung disease. NIPPV has been found useful in acute respiratory failure due to acute exacerbations of COPD, thoracic wall abnormalities and ARDS. It has not been found useful in hypoxemic respiratory failure due to interstitial lung disease and diffuse interstitial pneumonia.
\end{abstract}

MJAFI 2004; 60 : 224-226

Key Words : Acute respiratory failure; Arterial blood gases; Chronic obstructive pulmonary disease; Noninvasive positive pressure ventilation

\section{Introduction}

$\mathrm{N}$ oninvasive positive pressure ventilation is defined as technique of augmenting alveolar ventilation without introducing endotracheal tube, thereby avoiding complication due to endotracheal intubation. It is delivered by nasal route or facemask and is increasingly being used in the management of patients with acute and chronic respiratory failure. These portable, compact equipment that are less expensive and easily operable are useful as an intermediary between invasive ventilation and nasal facemask support to augment blood oxygenation. In acute respiratory failure, the precise mechanism elucidating how NIPPV improves gas exchange and systems is not fully known. Possible mechanisms include (a) resting of fatigued muscle thereby increasing lung compliance, tidal volume and minute ventilation [1-3]. (b) decrease work of breathing by overcoming effect of intrinsic positive end expiratory pressure (PEEP) in the inspiratory muscles [1-3]. The study was conducted to assess the efficiency of NIPPV in patients with acute respiratory failure including exacerbations of COPD whose condition did not improve with aggressive medical therapy.

\section{Material and Methods}

Patients requiring mechanical ventilatory support for hypoxemic and /or hypercapnic acute respiratory failure, managed with NIPPV in our Intensive Care Unit during August 1998 to April 2001 were selected for study. Criteria for selection were as follows: (a) respiratory rate more than $35 /$ minute, (b) presence of hypoxemia $\left(\mathrm{PaO}_{2}\right.$ less than $60 \mathrm{mmHg}$ and $\mathrm{SaO}_{2}$ less than $92 \%$ ) and/or (c) presence of respiratory acidosis $\left(\mathrm{PaCO}_{2}\right.$ more than $45 \mathrm{mmHg}$ and $\mathrm{pH}$ less than 7.35). Patients with hemodynamic instability, deep coma and those who were uncooperative were excluded from the study. The baseline clinical parameters were recorded in all patients. NIPPV was applied on spontaneous / time (S/T) mode via silicone mask, secured with strap. Ventilation support system used was Respironic's BiPAP S/T. IPAP and EPAP were set to achieve patient comfort. High flow oxygen $(61 / \mathrm{min})$ was delivered through a port in oro-nasal mask. During NIPPV patients were monitored for their comfort, level of dyspnoea, level of consciousness and respiratory rate. Arterial blood gases were determined in all patients at baseline. It was repeated after 2 hours and then daily. NIPPV was given continuously for 24 hours and then depending on response NIPPV was given intermittently and duration was reduced gradually.

"Classified Specialist (Medicine \& Respiratory Medicine), Military Hospital, Namkum, Ranchi-834010, ${ }^{+}$DDMS, Head Quarter 12 Corps (Med), C/o 56 APO, "Classified Specialist (Anaesthesiology), Army Hospital (R\&R), Delhi Cantt -110010. 
Improvement in arterial blood gases, requirement of inspiratory and expiratory positive airway pressures, duration of NIPPV, intubation, long term NIPPV and mortality were compared between COPD and non-COPD groups and results were analyzed using paired $\mathrm{t}$ test and $\mathrm{Z}$ test for significance.

\section{Results}

45 patients (29 males and 16 females) with acute respiratory failure treated with NIPPV were evaluated. Mean age was 68.32 years (range 29-82 years). Approximately two third of patients had acute respiratory failure due to exacerbation of COPD (29 patients). Etiology of acute respiratory failure in other patients was ARDS - 4 patients, severe kyphoscoliosis - 2 patients, ILD - 4 patients, lung contusion with pneumonia - one patient and thoracoplasty in one patient. It was used for difficult weaning in 4 patients who were on conventional ventilation for more than one month. 3 of these were due to COPD exacerbation and one patient had severe kyphoscoliosis.

Patients with COPD exacerbation were a decade older, predominantly male with severe respiratory acidosis whereas in other than COPD (non-COPD) group hypoxemia was more marked. Mean age in COPD group was 71 years (range 55-82 years) and in non-COPD group 61 years (range 29-80 years). There were 20 males and 9 females in COPD group as compared to 9 males and 7 females in non-COPD group.

There was statistically significant reduction in $\mathrm{PaCO}_{2}$ and $\mathrm{PaO}_{2}$ with NIPPV in both COPD and non-COPD groups at 24 hours (Table 1). Increase in $\mathrm{pH}$ was statistically significant only in COPD group. Patients with ILD did not show improvement and all 4 cases of ILD showed worsening of hypoxemia on NIPPV requiring intubation. Requirement of IPAP and EPAP were comparatively low in COPD group but statistically it was not significant (Table 2). More number of patients required intubation, long term intermittent NIPPV and expired in non-COPD group that was statistically significant. Minor complications were seen in 9 patients (nose abrasion-5, epistaxis-1, aerophagy-1 and upper gastrointestinal bleed in 2 patients).

\section{Discussion}

Numerous studies have focused on the use of NIPPV for acute respiratory failure. Important advantages of this technique include increased patient comforts, maintenance of airway defences, ability to eat and speak, and avoiding the complications of endotracheal intubation such as nosocomial pneumonia, injury to airways, aspiration and post intubation laryngeal and tracheal stenosis [4]. The disadvantages of NIPPV include slow improvement of blood gases [5], the need for conscious, cooperative patient and decreased ability to clear bronchial secretion. NIPPV should be instituted if the respiratory rate is more than 30 / minute and $\mathrm{pH}$ is less than 7.35. Successful treatment with NIPPV is associated with an increase in arterial $\mathrm{pH}$ and decrease in $\mathrm{PaCO}_{2}$ at two hours of treatment. If the variables do not improve, intubation should be considered [6].
Table 1

Improvement in ABG on NIPPV

\begin{tabular}{|c|c|c|c|c|}
\hline $\mathrm{ABG}$ & Base line & & $\begin{array}{l}\text { hour } \\
\text { value) }\end{array}$ & $\begin{array}{l}24 \text { hours } \\
\text { ( } \mathrm{p} \text { value) }\end{array}$ \\
\hline \multicolumn{5}{|c|}{ COPD $(\mathrm{N}=29)$} \\
\hline $\mathrm{PaO}_{2}$ & 61 & 63.08 & $(>0.05)$ & $67.35(<0.05)$ \\
\hline $\mathrm{PaCo}_{2}$ & 75.2 & 68.20 & $(<0.05)$ & $61.4(<0.01)$ \\
\hline $\mathrm{pH}$ & 7.26 & 30 & $(>0.05)$ & $7.34(<0.05)$ \\
\hline \multicolumn{5}{|c|}{ Non COPD $(\mathrm{N}=16)$} \\
\hline $\mathrm{PaO}_{2}$ & 51.5 & 52 & $(>0.05)$ & $57.17(<0.05)$ \\
\hline $\mathrm{PaCO}_{2}$ & 71 & 63 & $(>0.05)$ & $59.4(<0.05)$ \\
\hline $\mathrm{pH}$ & 7.29 & 7.30 & $(>0.05)$ & $7.33(>0.05)$ \\
\hline
\end{tabular}

Test of significance carried out using paired test

Table 2

NIPPV setting and outcome

$\begin{array}{lccl}\text { Parameters } & \begin{array}{c}\text { COPD } \\ (\mathrm{N}=29)\end{array} & \begin{array}{c}\text { Non COPD } \\ (\mathrm{N}=16)\end{array} & \mathrm{p} \text { value } \\ \text { IPAP }\left(\mathrm{cmH}_{2} \mathrm{O}\right) & 13.86 & 14.12 & \mathrm{NS} \\ \text { EPAP }\left(\mathrm{cmH}_{2} \mathrm{O}\right) & 5.2 & 6.2 & \mathrm{NS} \\ \text { NIPPV duration (days) } & 5.8 & 5.1 & \mathrm{NS} \\ \text { Intubation (No) } & 8 & 7 & <0.05 \\ \text { Deaths (No) } & 5 & 4 & <0.05 \\ \text { Long term NIPPV } & 8 & 3 & <0.05\end{array}$

$\mathrm{Z}$ test used for significance, NS - not significant

Acute respiratory failure due to exacerbation of COPD is the most commonly studied group for NIPPV [5-9]. Two third of our patients belonged to this group. 8 patients $(28 \%)$ did not show improvement and required intubation. Results are comparable to other studies. The need for endotracheal intubation was significantly less in COPD exacerbation as compared to non-COPD group in which 7 patients (44\%) required intubation. ABG showed statistically significant improvement in acid-base status, hypercapnia and hypoxia at 24 hours in patients of COPD exacerbation treated with NIPPV. One of the possible mechanisms how NIPPV improves gas exchange and symptoms, includes decreased work of breathing by overcoming the effect of PEEP on the inspiratory muscles [1-3]. Patients with COPD often exhibit this phenomenon. Possibly that is the reason why COPD group benefit most by NIPPV. Success rate as per various studies in patients with COPD exacerbation has been $31-88 \%$. Critical factors in the success of these studies have been the selection of patients who are cooperative [8], hemodynamically stable, able to protect their airways and do not have excessive secretion. Since the entry criteria have been different in these studies, it is difficult to compare results from these studies. In the study of Meduri et al [10] of 18 patients, a $\mathrm{pH}$ value of more than 7.30 at two hour predicted success of NIPPV with positive predictive value of $92 \%$. Ambrosino et al [4] found base line pH 7.28 Vs 7.22 in whom it was 
unsuccessful. In present study, mean $\mathrm{pH}$ at two hour was 7.30.

The data on use of NIPPV for other forms of acute respiratory failure are less clear, with one study showing a significant decrease in avoiding endotracheal intubation and one showing no difference [8,11]. NIPPV has been used successfully in a wide variety of respiratory failure due to asthma, pneumonia, post operative respiratory failure, early ARDS, restrictive chest wall disease, cardiogenic pulmonary edema and weaning from mechanical ventilation. The largest series of patients treated by NIPPV was reported by Meduri et al [12]. They showed improved gas exchange and avoidance of intubation in patients with a variety of clinical conditions.

Difficulty in weaning leads to repeated endotracheal intubation [10,13-15]. Udwadia et al [13] used NIPPV as a weaning modality in difficult to extubate patients. Of 20 patients who were treated with NIPPV only 2 required reintubaion. We used NIPPV successfully to wean off 4 patients (COPD exacerbation - 3, severe kyphoscoliosis-1) who were on conventional ventilation for more than one month.

Application of NIPPV may avoid intubation in some patients with ARDS $[16,17]$. Application of CPAP of 5 $\mathrm{cm}$ of $\mathrm{H}_{2} \mathrm{O}$ leads to significant improvement in $\mathrm{PaO}_{2} /$ $\mathrm{FiO}_{2}$ ratio within one hour of therapy [16]. Out of 4 ARDS cases, 2 required intubation in the present study.

None of the studies mention about the role of NIPPV in hypoxemic respiratory failure as a result of interstitial lung disease. We tried NIPPV in four such patients. All of them showed deterioration in blood gases at two hour requiring intubation.

NIPPV represents a significant advance in the treatment of selected patients with acute respiratory failure. We found it very useful in acute respiratory failure due to COPD exacerbation. thoracic cage abnormalities and ARDS. It is very helpful in patients who are difficult to wean. It has not been found useful in hypoxemic respiratory failure due to interstitial lung disease and diffuse interstitial lesions.

\section{References}

1. Appendini L, Patessio A, Zanaboni S et al. Physiologic effects of positive end expiratory pressure and mask pressure support during exacerbations of chronic obstructive pulmonary disease. Am J Respir Crit Care Med 1994;149:1069-76.

2. Carrey Z, Gottfried SB, Levy RD. Ventilatory muscle support in respiratory failure with nasal positive pressure ventilation. Chest 1990;97:150-58.

3. Brochard L, Isabey D, Piquet $J$ et al. Reversal of acute exacerbations of COPD by inspiratory assistance with a face mask. N Engl J Med 1990;323:1523-30.

4. Ambrosino N, Foglio K, Rubini F et al. Non-invasive mechanical ventilation in acute respiratory failure due to COPD: correlates for success. Thorax 1995;50:755-7.

5. Robert MJ, John ML, Michael AM. Noninvasive positive pressure ventilation for acute respiratory failure. Underutilized or overrated? Chest 1997;111:1672-8.

6. Baudouins, Blumenthal S, Cooper B et al. Noninvasive ventilation in acute respiratory failure - British Thoracic Society Guideline. Thorax 2002;57:192-211.

7. Bott J, Carroll MP, Conway JH et al. Randomized controlled trial of nasal ventilation in acute respiratory failure due to COPD. Lancet 1993;341:1555-7.

8. Kramer N, Meyer TJ, Meharg J et al. Randomized prospective trial of noninvasive positive pressure ventilation in acute respiratory failure. Am J Respir Crit Care Med 1995;151:17991806.

9. Brochard I, Mancebo J, Wysocki M et al. Noninvasive ventilation for acute exacerbations of COPD. N Engl J Med 1995;333:817-22.

10. Meduri GU, Abou-Shala N, Fox RC et al. Noninvasive face mask mechanical ventilation in patients with acute hypercapnic respiatory failure. Chest 1991;100:445-54.

11. Wysocki M, Tric L, Wolff MA et al. Noninvasive pressure support ventilation in patients with acute respiratory failure: a randomized comparison with conventional therapy. Chest 1995;107:761-8.

12. Meduri GU, Turner RE, Abou-Shala N et al. Noninvasive positive pressure ventilation via face mask: first-line intervention in patients with acute hypercapnic and hypoxemic respiratory failure. Chest 1996;109:179-93.

13. Udwadia ZF, Santis GK, Steven MH et al. Nasal ventilation to facilitate weaning in patients with chronic respiratory insufficiency. Thorax 1992;47:715-8.

14, Nava S, Ambrosino N, Clini E et al. Noninvasive mechanical ventilation in the weaning of patients with respiratory failure due to chronic obstructive pulmonary disease. A randomized controlled trial. Ann Intern Med 1998;128:721-8.

15. Girault C, Daudenthun I, Chevron V et al. Noninvasive ventilation as a systematic extubation and weaning technique in acute-on-chronic respiratory failure. Am J Respir Crit Care Med 1999;160:86-92.

16. Coveilli Hd, Weled BJ, Beekman JF. Efficacy of continuous positive airway pressure administered by face mask. Chest 1982;81:147-50.

17. Rocker G, Mackenzie MG, Williams B et al. Noninvasive positive pressure ventilation. Successful outcome in patients with acute lung injury/ARDS. Chest 1999;115:173-7. 